\title{
Computational fluid dynamic modelling of the Frood-Stobie ice stope thermal storage for mine ventilation heating
}

\author{
K Trapani Mining Innovation, Rehabilitation and Applied Research Corporation (MIRARCO), Canada \\ Z Chen Laurentian University, Canada
}

\begin{abstract}
Deep mines are subject to increased heat loads from the ventilation air, which undergoes auto-compression and increases approximately $1^{\circ} \mathrm{C}$ per $100 \mathrm{~m}$. Also, mines located in sub-arctic climates require the mine ventilation air to be heated in winter to ensure that icing does not occur within the ventilation shaft. Ice stopes, a system by which ice is created underground by spraying warm return service water onto the cold incoming air in winter, can be utilised for both heating and cooling. The ice storage can be maintained till cooling is required in summer, at which point the ice is melted and the resulting chilled water is similarly sprayed onto the oncoming ventilation air to cool it down, in a bulk air cooler. Computations fluid dynamics simulation, using ANSYS Fluent, was conducted to allow more control on the system and optimise the ice creation within the stope. Simulation results showed higher snow yields and heat transfer efficiencies in colder temperatures with simulations conducted for -5 to $-30^{\circ} \mathrm{C}$. The maximum air temperature which could be achieved at the stope air outlet, while still resulting in the water particles being fully frozen, was approximately $-2.2^{\circ} \mathrm{C}$. A linear correlation could be derived between the optimal water flow rate required (for maximum heating and ice fraction of one) and the inlet air temperature, allowing some control on the system's performance. Future work will concentrate on establishing the best water spray parameters to melt the ice within the stope and produce chilled water to be used in the bulk air cooler.
\end{abstract}

Keywords: ice stope, natural thermal storage, mine heating, mine HVAC (heating, ventilation and air conditioning)

\section{Introduction}

There are various heat sources that need to be considered when designing the heating, ventilation and air conditioning (HVAC) system of underground mines, along with government regulations which stipulate the temperatures for the underground workings (ACGIH 2011) and threshold limit values (TLVs) for contaminates in the air, and therefore the air exchanges required. A majority of the temperature increase underground is attributable to auto-compression of the ventilation air, at approximately $10^{\circ} \mathrm{C}$ temperature rise per kilometre the air travels underground. So with deep mines, at potentially $2.5 \mathrm{~km}$ or more in depth, even in sub-zero temperatures the air would have to be cooled before reaching the workings underground since at the shaft collar intake the incoming air cannot be less than $0^{\circ} \mathrm{C}$ due to safety hazards associated with icing within the ventilation mine shaft.

This creates a situation where the air would be required to be heated at the surface and cooled down underground, resulting in a high proportion of the energy consumed in the mine dedicated towards conditioning of the ventilation air. So achieving adequate air conditioning of deep mines all year round could be very costly, especially if these are in remote locations with energy derived from diesel generators/boilers (Paraszczak \& Fytas 2012). This paper will outline the potential of ice stopes, a natural thermal storage system, for provision of the heating and cooling loads in underground mines located in subarctic climates. 


\section{Ice stopes}

'Ice stopes' came to be known by that name since they traditionally utilised depleted mining stopes in which to generate, store and deplete the ice, essentially creating a seasonal natural thermal storage. The generation of ice in the stope is the process by which the ventilation air is heated, while the depletion of the ice is the process by which cooling occurs. Historically these stopes were mainly used for heating, since the mines in which they were installed were not deep enough to require ventilation air cooling.

\subsection{Heating and cooling process}

The air is heated in the stope by spraying warm return service water from the mine, at about $10^{\circ} \mathrm{C}$, onto the sub-zero cold intake ventilation air. Through convection, mass and heat transfer occurs resulting in the air becoming more saturated and the water droplets releasing energy to the air, dropping gradually to $273.15 \mathrm{~K}$ $\left(0^{\circ} \mathrm{C}\right)$ where the droplets start changing phase from liquid to solid. This heating process is illustrated in Figure 1 . Ice is accumulated throughout this process, filling the storage volume by about $75 \%$ of its capacity.

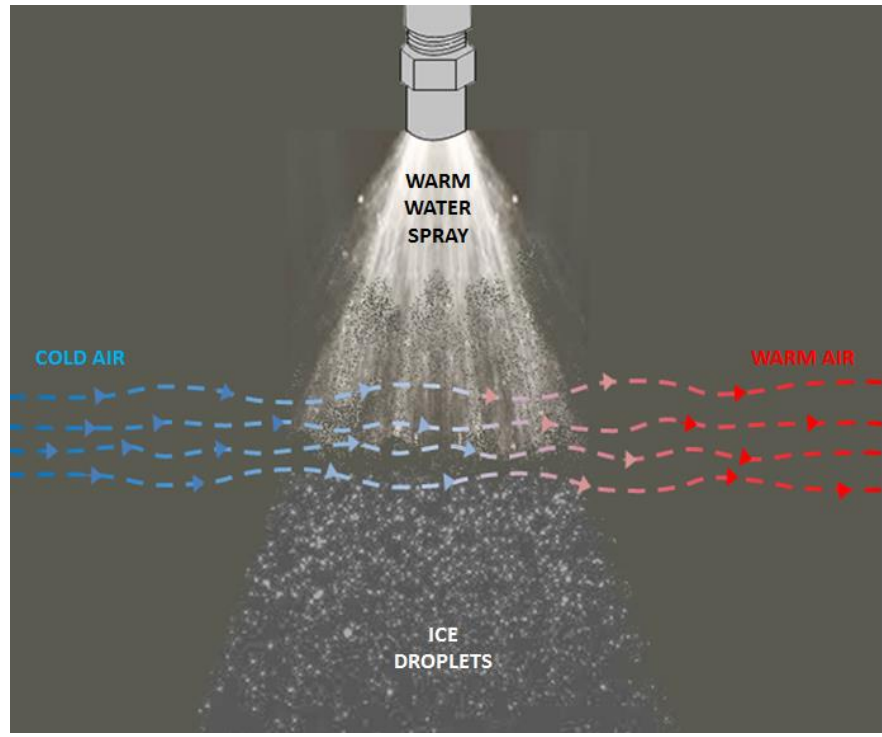

Figure 1 Diagram showing heating process in the ice stope

In summer this ice can then be used to provide the cooling necessary. Observations have shown that simple passing of air over the ice pile does not result in a significant drop in air temperature (Stachulak 1991), due to the minimal contact surface area, with a substantial amount of cooling potential being lost in chilled water/ice slurry being drained from the stope. To maximise utilisation of this cooling, an optimised design would be needed to maximise the surface area available for heat transfer to take place. This could be achieved by implementing a bulk air cooler that sprays the chilled water onto the incoming warm ventilation air, hence cooling the air down. The availability of chilled water used in the bulk air cooler, from the ice stope, could be controlled by spraying water onto the ice to melt it and, so, increasing the flow of chilled water coming out of the stope. The increased surface area, from the water spray in the bulk air cooler, allows significantly more heat transfer to occur, relative to the air being passed over an ice pile within the stope.

\subsection{Historical developments}

The first ice stope to be installed was at the Horne mine in Rouyn-Noranda, Quebec (Bischoff 1947) and this was operational from 1942 till the mine's closure in 1976. The stope was $45 \mathrm{~m}$ in depth and had a capacity for 100,000 tonnes of ice. The freezing efficiency ranged from $20-50 \%$, being more efficient in colder temperatures, with an air flow of $85 \mathrm{~m}^{3} / \mathrm{s}$. Attempts were made to utilise the ice produced for summer cooling but the system was not well designed and sufficiently optimised to provide any significant reduction 
in temperature. Plans were proposed for a counter-current flow using an adjacent stope, which would have significantly increased the system's thermal efficiency, but was never implemented.

Following the success of the ice stope at the Horne mine, a two stope system was installed at the Frood-Stobie mine in Sudbury in 1955 (Stachulak 1991) and has been operational ever since. A diagram of the system is depicted in Figure 2. This stope is about $60 \mathrm{~m}$ in depth and has a storage capacity of 145,000 tonnes of ice - significantly larger than the Horne mine ice stope. The system was designed exclusively for winter heating, and air was passed through the stope in summer only to melt the ice and empty the stope. The average freezing efficiency was calculated to be approximately $56 \%$, when considering the average flow of water in the stope was $19 \mathrm{~kg} / \mathrm{s}$ during the 1,200 hours of operation during the winter heating. A 4:1 ratio by volume of compressed air is sprayed with the water at the spray orifice, to break the water particles to a fine mist, which allows them to quickly turn into ice when exposed to the cold ventilation air. Strainers are installed in the water supply lines to prevent freezing blockage. Nozzles are installed on a track, so that they can be lowered for maintenance purposes.

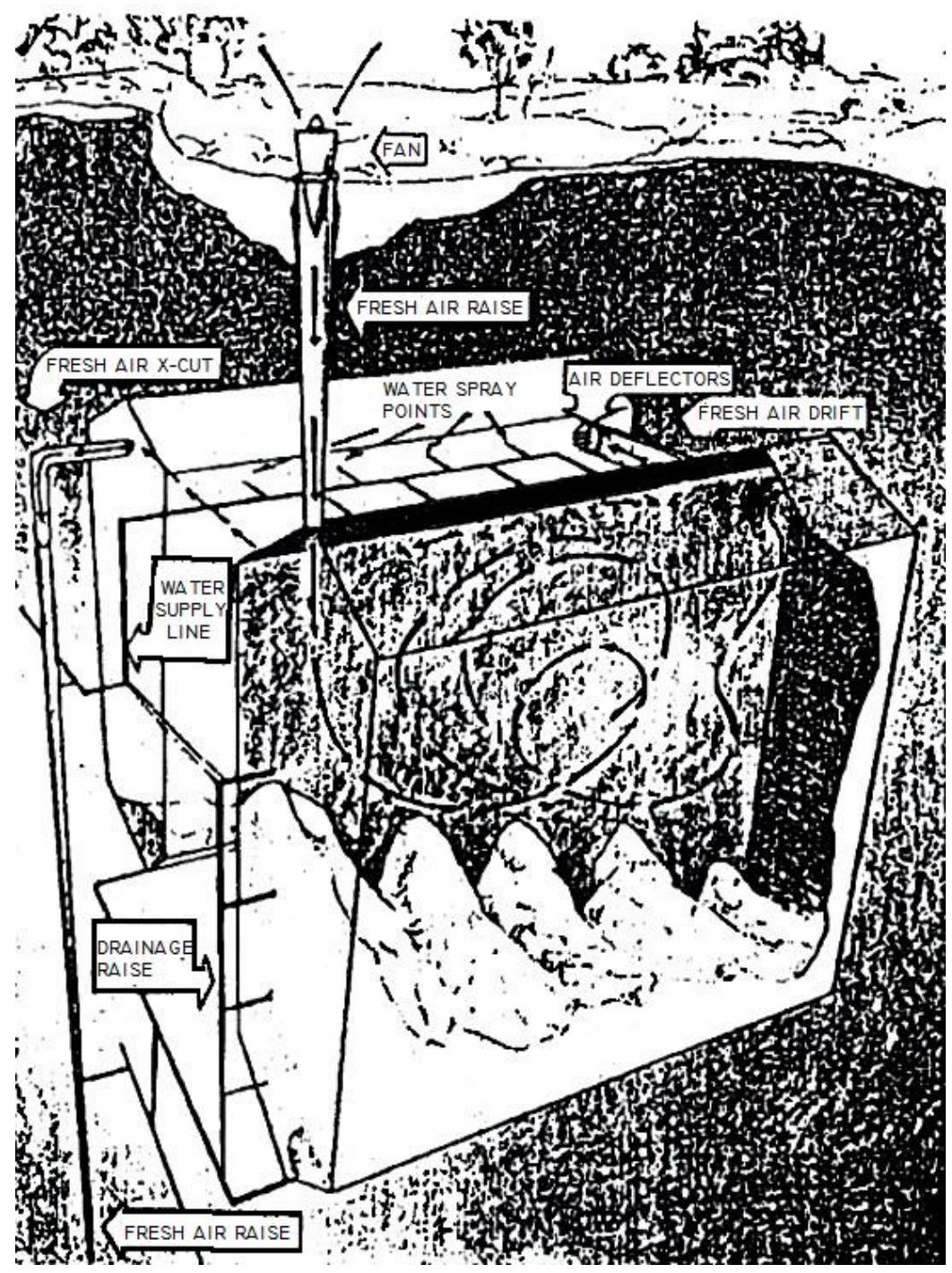

Figure 2 Graphical illustration of the Frood-Stobie ice stope (Stachulak 1991)

At the Frood-Stobie site, research was recently conducted to replicate the ice stope above ground in an insulated container, which was named the Modular Thermal Transfer Unit (MTTU). The main objective was to reduce the maintenance cost of the underground ice stope by having it above ground, where it is more easily accessible. The MTTU is $1 / 12$ th the scale of the underground ice storage, having a heating capacity of $900 \mathrm{~kW}$ throughout the winter (Allen et al. 2012). It employed a variable flow pump to control the flow of 
water relative to the temperature of the incoming air flow. At the Frood-Stobie ice stope, this control was maintained by closing some of the spray lines and, hence, decreasing the overall mass flow of water entering the stope.

\section{Computational fluid dynamics modelling}

Computational fluid dynamics (CFD) modelling was conducted to study the freezing of the water droplets in the cold air stream, in an attempt to optimise the heat transfer between the two fluids and maximise the generation of ice available for summer cooling. This needed to consider mixing and heat transfer of multi-phase fluids, in this case water/ice and air. For the CFD modelling, ANSYS ${ }^{\circledR}$ Academic Research, version 16.2 (ANSYS ${ }^{\circledR}$ Inc. 2016) was used, primarily due to its ability to handle multi-phase fluids and the versatility of introducing user-defined functions (UDFs). The water spray was modelled using Fluent's particle injections interface, with the particle properties defined by the UDF.

\subsection{User-defined function}

Thermodynamic principles indicate that cooling/heating with water spray is mainly a result of convective and conductive heat transfer. Mass transfer occurs between the water and air stream, with the air increasing its capacity to absorb moisture as it increases in temperature. The reduction/increase in energy in the water particles and air stream is calculated from the heat transfer coefficient and the mass transfer coefficient of the water vapour in the air.

The heat transfer coefficient, $h$ is calculated from:

$$
h=\frac{N u \cdot k}{d}
$$

where:

$N u$ is the Nusselt number $(N u=2+0.6 \sqrt{R e} \cdot \sqrt[3]{P r})$.

$R e$ is the Reynolds number.

$\operatorname{Pr}$ is the Prandtl number.

$k$ is the thermal conductivity.

and $d$ is the characteristic length (diameter of droplets in this case).

Similarly, the mass transfer coefficient, $k_{m}$ was derived from:

$$
k_{m}=\frac{(2+0.6 \sqrt{R e}) \cdot \sqrt[3]{S c} \cdot D}{2 \cdot d}
$$

where:

$S c$ is the Schmidt number.

$D$ is the diffusion coefficient.

$d$ is the droplet diameter.

From the mass transfer coefficient, the vaporisation rate of the water in the air can be estimated, allowing determination of the air and water dynamic properties within each computational cell. The calculation logic flow is illustrated in Figure 3 . The processes are distinctly split in the heat and mass transfer process, resulting in the heating/cooling of the air, and the process of solidification of the water particles, which takes into consideration the enthalpy each water particle results in. While solidification occurs, the UDF code loops through the process, reiterating the 'heat lost' to the surrounding air and calculating what volume fraction of the particle is solid or liquid. 


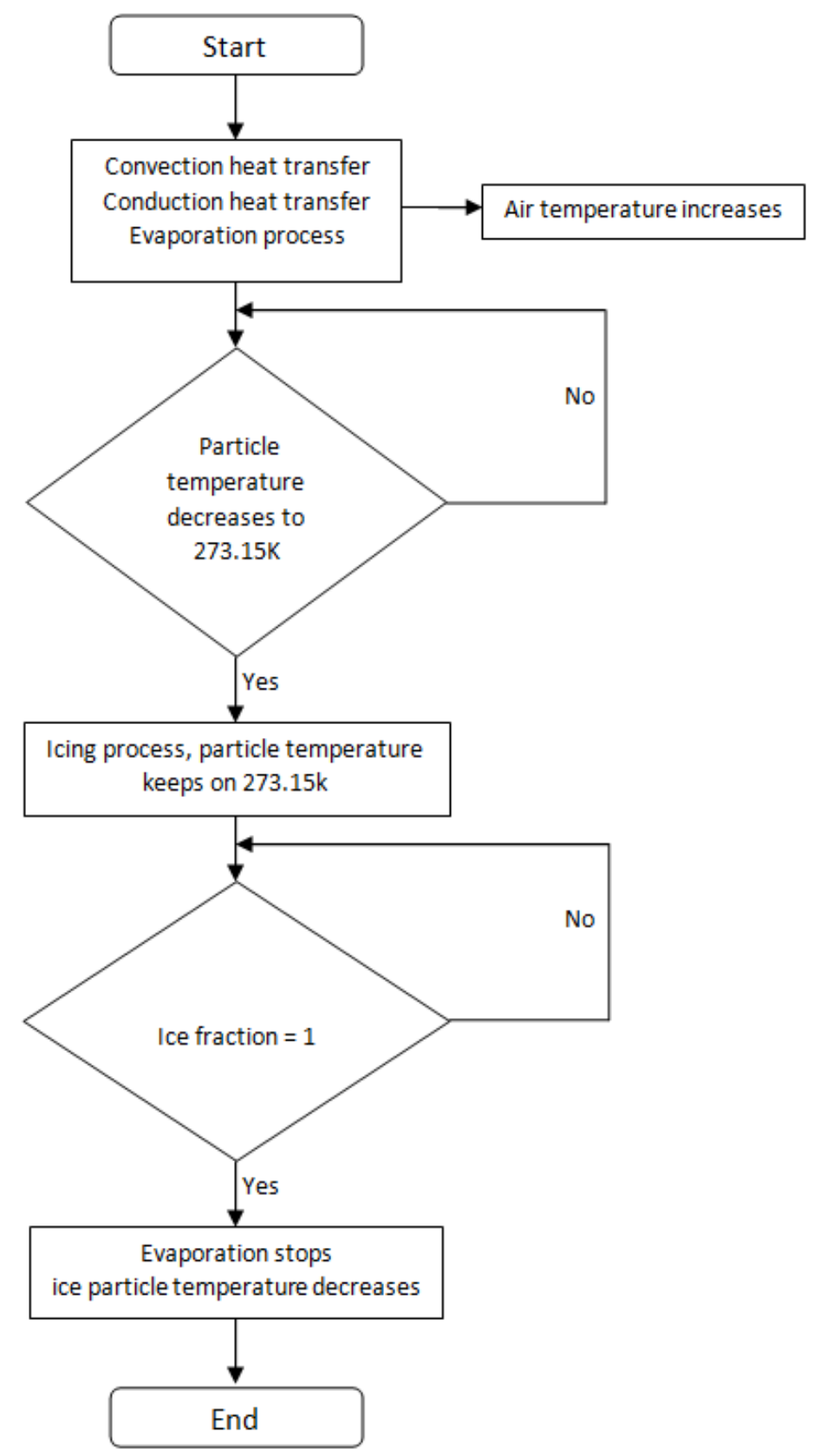

Figure 3 Logic flow chart for ANSYS Fluent UDF, representing the cooling process by which heat is transferred from the water particles to the air, with solidification considered into the process

\subsection{Model geometry}

The geometry was modelled to replicate a single stope at Frood-Stobie, to allow validation of the CFD model from published results (Sylvestre 1989). The stope dimensions are $61 \mathrm{~m}$ in length and height, and $24.4 \mathrm{~m}$ in width. The fresh air intake to the stope is located at the top and has an aperture of $6.1 \mathrm{~m}$. The air outlet, also $6.1 \mathrm{~m}$ in diameter, was located at the top of the front side of the stope. This is illustrated in Figure 4 . The water is sprayed from 10 nozzles and the water apertures were taken to be equally distributed at the top face of the geometry; with a spray orifice of $9.5 \mathrm{~mm}$. 


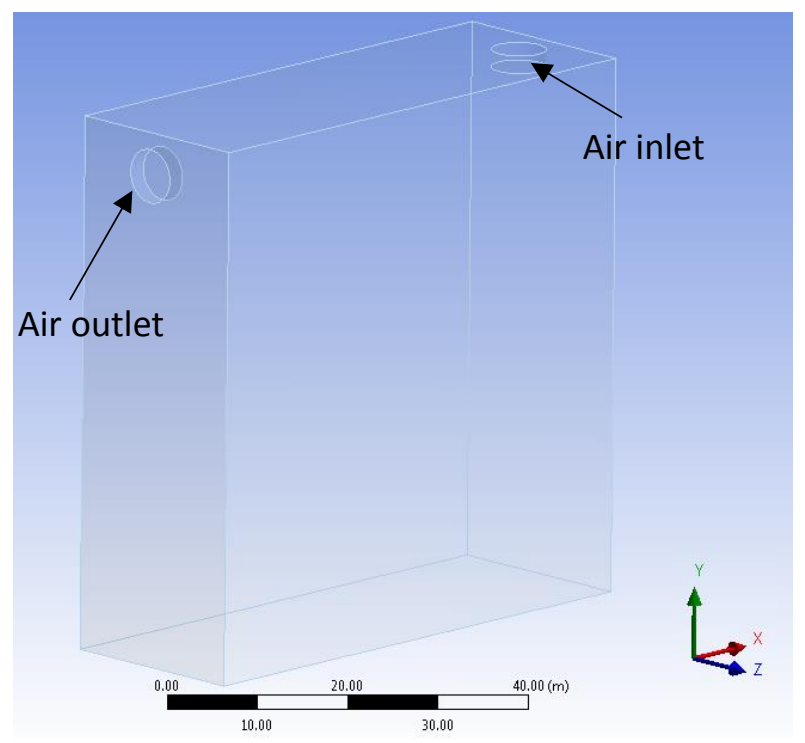

Figure 4 Model geometry of ice stope for CFD

\subsection{Model simulation}

\subsubsection{Model validation}

The validation of the CFD model was conducted for peak warming conditions, i.e. for conditions at which the atmospheric temperature was the coldest. The boundary conditions being:

- Air inlet temperature $=-28.9^{\circ} \mathrm{C}$.

- Air flow rate $=292 \mathrm{~kg} / \mathrm{s}$.

- Water inlet temperature $=7.8^{\circ} \mathrm{C}$.

- Water flow rate $=15 \mathrm{~kg} / \mathrm{s}$ per stope.

- Water particle diameter $=1 \mathrm{~mm}$.

Transient modelling of the stopes was conducted until the average outlet temperature from the stopes reached steady state, this occurred after approximately 1,000 time steps (which for the first 1500 time steps correspond to 1500s), as illustrated in Figure 5. Looking closely at the graph in Figure 5, one can notice a slight dip in the initial outlet temperature, this is due to the initial temperature within the domain, which was taken to be $-5^{\circ} \mathrm{C}$.

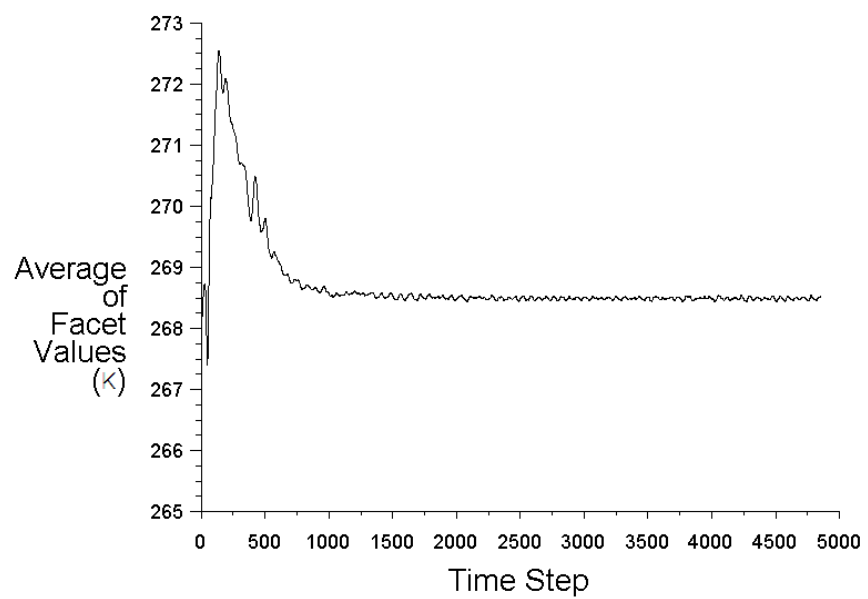

Figure 5 Stope average outlet temperature graph in Kelvin (K), simulated at -28.9 and $7.8^{\circ} \mathrm{C}$ for the air $(300 \mathrm{~kg} / \mathrm{s})$ and water $(30 \mathrm{~kg} / \mathrm{s})$ fluids respectively 
For these conditions, when the average outlet temperatures reaches steady state, the water particles are fully frozen a third of the way down the stope, with no flash freezing being characterised at the spray outlet. This is visually represented in Figure 6, which shows the frozen mass fraction of the water particle trace lines along the stope.
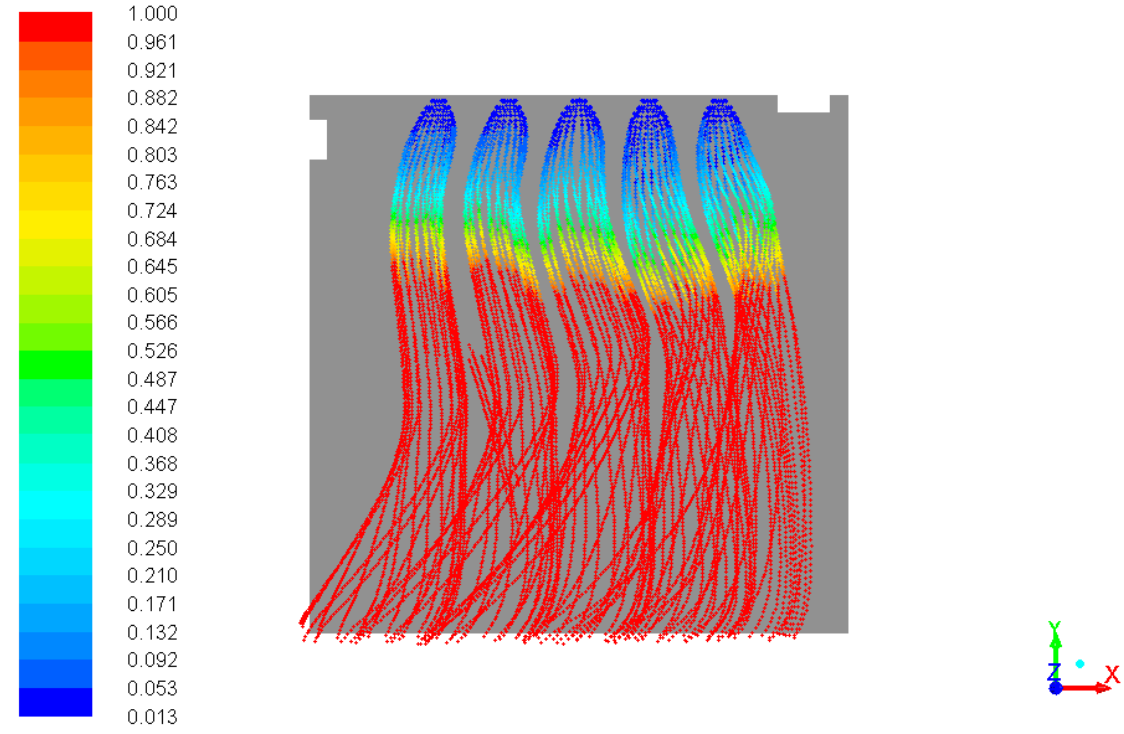

Figure 6 Ice mass fraction within stope, simulated at -28.9 and $7.8^{\circ} \mathrm{C}$ for the air $(292 \mathrm{~kg} / \mathrm{s})$ and water $(30 \mathrm{~kg} / \mathrm{s})$ fluids respectively

The heat transfer efficiency between the two fluids was estimated to be approximately $70 \%$, from comparison of the enthalpies at the air and water's inlet and outlet, with the air warming to $\sim 4.5^{\circ} \mathrm{C}$. The resulting air temperatures are slightly lower than the operational values at Frood-Stobie, especially in the beginning of the season, which might be mostly due to the stope boundary taken to be adiabatic whereas in reality it offers some heating from the surrounding rock mass. Also, the $100 \mathrm{~m}$ shaft to the stope should result in a $1^{\circ} \mathrm{C}$ rise in the air temperature, due to auto-compression, which was not accounted for. A graphical representation of the air temperatures within the stope is given in Figure 7. The contours show that most of the heating occurs in the upper part of the stope, when the water particles are still liquid. In this region the humidity levels are higher, when the air temperatures increase, the saturation pressure also increases, allowing more moisture to be absorbed resulting in higher absolute humidity.
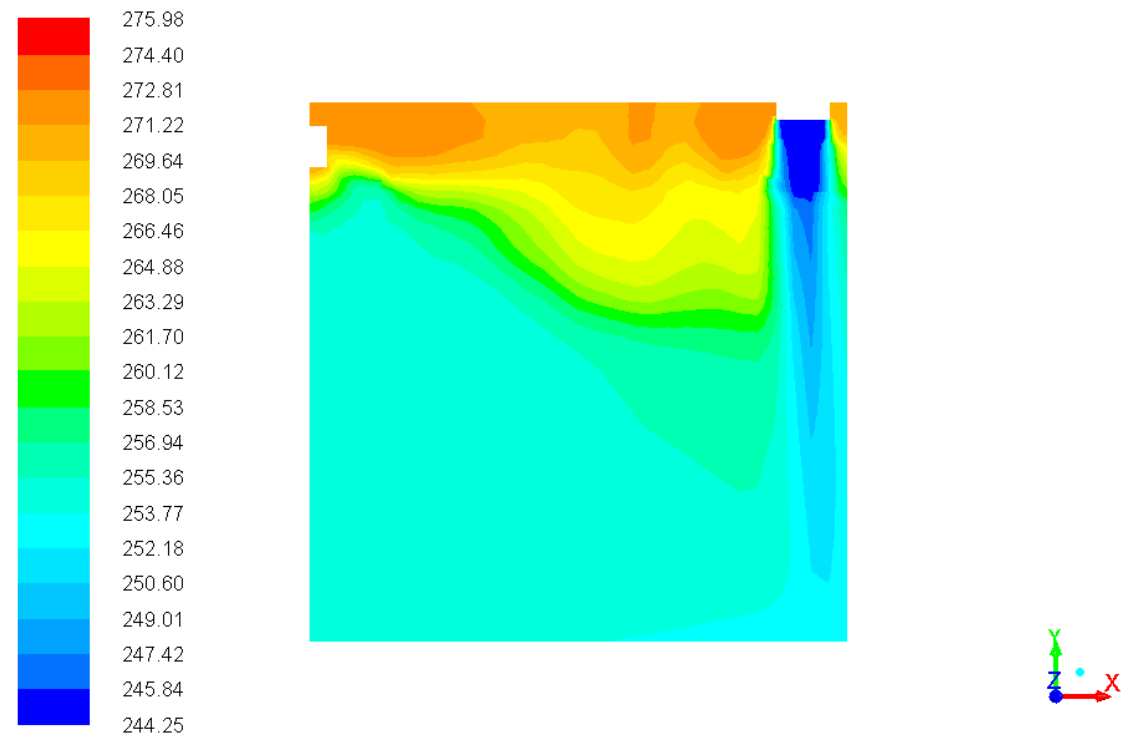

Figure 7 Air temperatures $(\mathrm{K})$ contours for the stope domain, simulated at -28.9 and $7.8^{\circ} \mathrm{C}$ for the air $(292 \mathrm{~kg} / \mathrm{s})$ and water $(30 \mathrm{~kg} / \mathrm{s})$ fluids respectively 
Analysis of the air velocity vector, highlighted in Figure 8, shows air moving in a circular fashion within the stope representing the air rising as it is being heated up and falling as it comes in contact with the incoming air stream and cooling back down. This residency time of the air particles before they exit the stope is $120 \mathrm{~s}$, the pathline showing that the air particles loop around the stope a couple of times before exiting at $-4.5^{\circ} \mathrm{C}$.
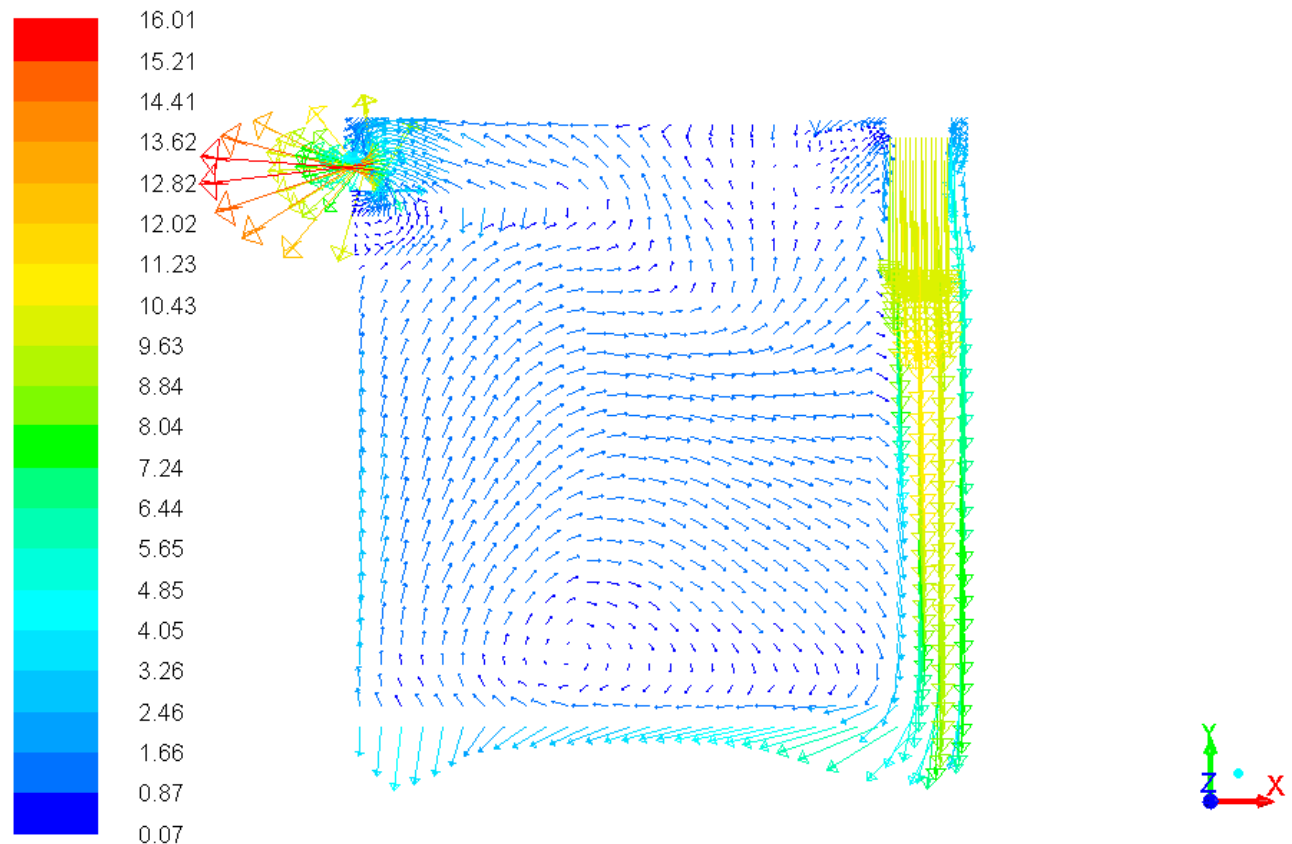

Figure 8 Air velocity vector $(\mathrm{m} / \mathrm{s})$ within stope, simulated at -28.9 and $7.8^{\circ} \mathrm{C}$ for the air $(292 \mathrm{~kg} / \mathrm{s})$ and water $(30 \mathrm{~kg} / \mathrm{s})$ fluids respectively

\subsubsection{Effect of particle diameter}

Simulation testing was conducted using the parameters of the validated model to assess the effect particle diameter has on the air outlet temperature. Particle diameters were varied from 2.5 to $0.5 \mathrm{~mm}$. At $0.5 \mathrm{~mm}$ the particles were flash freezing resulting in the nozzle aperture and air outlet getting blocked by ice. Results are illustrated in Figure 9, showing that heat transfer is most effective with smaller water particle diameters, while larger particle diameters do not provide a large enough surface area for heat transfer. Maximum air outlet temperature was achieved with a water particle diameter of $1 \mathrm{~mm}$, indicating this to be the optimal diameter for this application.

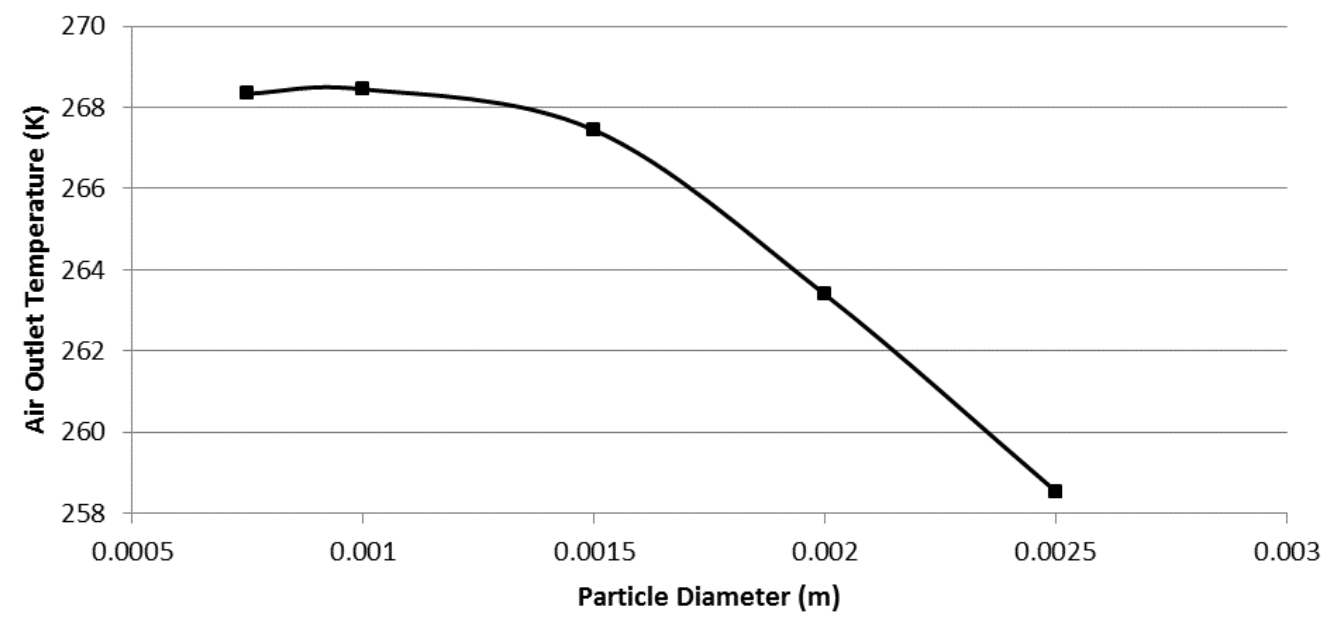

Figure 9 Air outlet temperature $(\mathrm{K})$ with varying water particle diameter $(\mathrm{m})$, simulated at -28.9 and $7.8^{\circ} \mathrm{C}$ for the air $(292 \mathrm{~kg} / \mathrm{s})$ and water $(30 \mathrm{~kg} / \mathrm{s})$ fluids respectively 


\subsubsection{Ventilation heating modelling with air temperatures -30 to $-5^{\circ} \mathrm{C}$}

Various boundary conditions were investigated to evaluate the system design conditions to be able to heat the ventilation air within the stope from -30 to $-5^{\circ} \mathrm{C}$. The goal of the simulations was to achieve the highest heating temperatures, while ensuring that the water particle droplets are fully frozen midway through the stope (to avoid water drainage issues) and without flash freezing occurring at the spray nozzle outlet. A particle diameter of $1 \mathrm{~mm}$ was found to be the most effective, so testing with different flow rates and inlet air temperatures maintained this particle diameter. The main boundary conditions that were maintained constant throughout are as follows:

- Air flow rate $=292 \mathrm{~kg} / \mathrm{s}$.

- Water inlet temperature $=7.8^{\circ} \mathrm{C}$.

- Water particle diameter $=1 \mathrm{~mm}$.

For freezing conditions (midway through the stope), the maximum outlet air temperature that could be achieved was $\sim 271 \mathrm{~K}$, which is also in the range of the maximum temperatures achieved at Frood-Stobie; reported to be -2.2 to $-0.5^{\circ} \mathrm{C}$ (Stachulak 1991). The required water mass flow rates to achieve this level of heating are shown in Figure 10. The simulation results indicate a linear trend in the required water flow rate for increased heating capacity (the air temperature difference from outlet to inlet). From the trend line, an equation can be derived from a stope of this size, from which estimates of the water flow for optimal heating can be generated to ensure that ice fraction within the stope is maintained close to one, reducing maintenance impacts due to water drainage and ensuring higher heat transfer efficiencies.

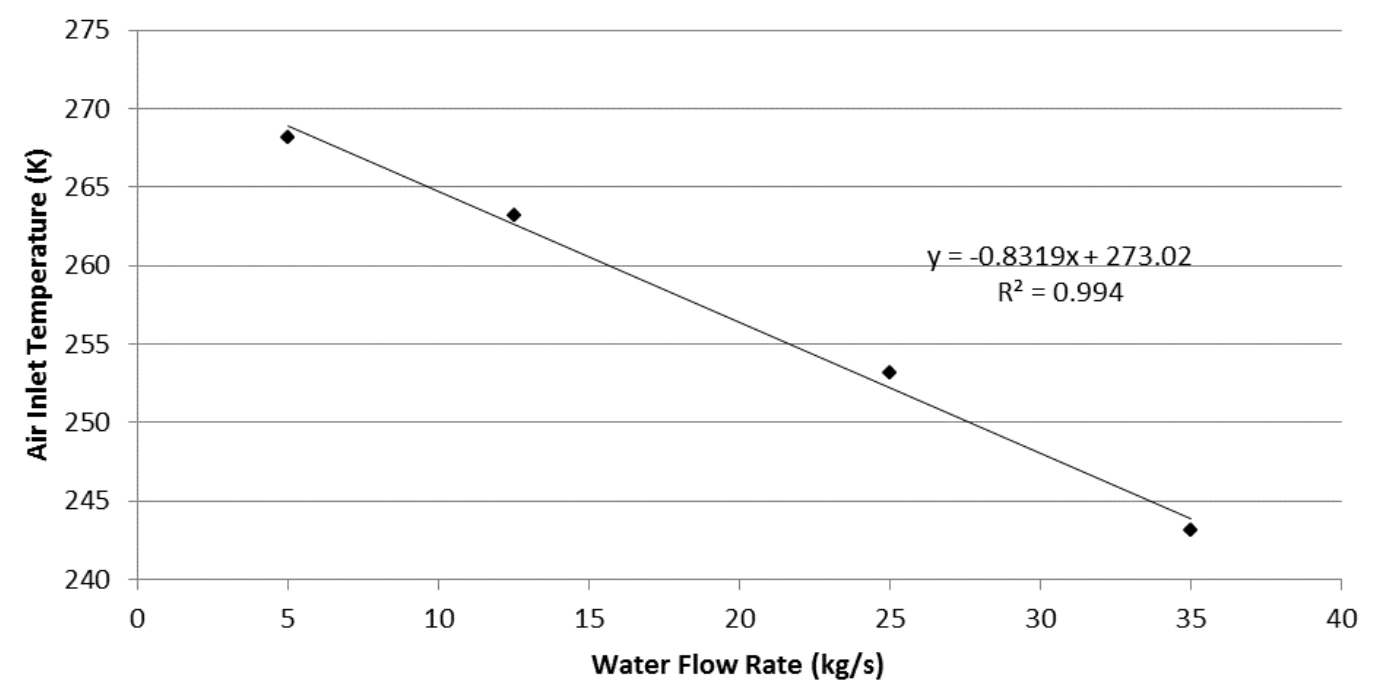

Figure 10 CFD simulation results showing the required water flow rate to achieve maximum heating for varying air inlet temperatures, while maintaining freezing conditions midway through the stope

The heat transfer efficiency ranged from $70-54 \%$ for the simulation studies conducted, with the air temperature in the -30 to $-5^{\circ} \mathrm{C}$ range. In colder temperatures, with the greatest temperature difference between the inlet air and water temperatures, higher heat transfer efficiencies could be attained. The gradient of the heat transfer efficiency shows a rapid decrease as it approaches $0^{\circ} \mathrm{C}$, mostly due to the capacity of heat available for heat transfer decreasing.

\section{Conclusion}

The main motivation in the implementation of the ice stope is that both heating and cooling could be derived from it at a minimal operational cost, since the only work input required is pumped water. Ensuring optimal ice creation during the winter heating period, results in higher heat transfer efficiency between the two fluid mediums and more ice availability for summer cooling. Literature data available for the Frood-Stobie ice 
stope (Stachulak 1991) allowed some comparative studies to be conducted for a replica of the stope with CFD simulation, and hence validation of the UDF developed for this particular application.

A number of simulation studies were conducted for the stope, with water particle diameter, air input temperature and water flow rates changing for the different studies. When testing the varying water particle diameters the optimal diameter was $1 \mathrm{~mm}$, at which maximum heat transfer could be achieved. For the series of simulations, a linear trend could be established between the mass flow rate and the air inlet temperature, with the resultant conditions achieving an approximate outlet temperature of $-2.2^{\circ} \mathrm{C}$ and the water particles being fully frozen midway through the stope.

Future work will focus on the cooling process within the ice stope, through thermal simulations of the ice pile as a porous medium. Mainly to optimise the melting process of the ice and availability of chilled water to be used in the bulk air cooler to cool the mine's ventilation air.

\section{Acknowledgement}

The authors thank the Ultra Deep Mining Network (UDMN) for their financial contribution and support to this research.

\section{References}

ACGIH (American Conference of Governmental Industrial Hygienists) 2011, Heat stress and strain: documentation of TLVs and BEIs, American Conference of Governmental Industrial Hygienists, Cincinnati.

Allen, C, Morgan, J \& Rantanen, E 2012, 'Modular thermal transfer unit (MTTU) - Portable surface ice stope', in F Calizaya \& M Nelson (eds), Proceedings of the 14th U.S./North American Mine Ventilation Symposium 2012, University of Utah, Salt Lake City, pp. 359-364.

ANSYS, Inc. 2017, ANSYS ${ }^{\circledR}$ Academic Research, version 16.2, Help System, Fluent 6.3 Documentation, Canonsburg, Pennsylvania.

Bischoff, CT 1947, 'Progress in underground air conditioning at Noranda', Transactions of the Canadian Institute of Mining and Metallurgy and the Mining Society of Nova Scotia, pp. 23-35.

Paraszczak, J \& Fytas, K 2012, 'Renewable energy sources - a promising opportunity for remote mine sites?', Proceedings of the International Conference on Renewable Energies and Power Quality, 28-30 March, Santiago de Compostela, Spain.

Stachulak, J 1991, 'Ventilation strategy and unique air conditioning at Inco Limited', CIM Bulletin, Canadian Institute of Mining and Metallurgy, vol. 84, no. 950, pp. 41-45.

Sylvestre, MJ 1989, Heating and Ventilation Study of INCO's Creighton Mine Department of Mining and Metallurgical Engineering, PhD thesis, McGill University, Montreal. 